\title{
The Genetics of White Matter Lesions
}

\author{
Arezoo Assareh ${ }^{1,2}$, Karen A. Mather ${ }^{2}$, Peter R. Schofield ${ }^{1,3}$, John B.J. Kwok ${ }^{1,3}$, \& Perminder S. Sachdev ${ }^{2,4}$ \\ 1 Neuroscience Research Australia, Sydney, Australia \\ 2 Brain and Ageing Research Program, School of Psychiatry, University of New South Wales, Sydney, Australia \\ 3 School of Medical Science, University of New South Wales, Sydney, Australia \\ 4 Neuropsychiatric Institute, Prince of Wales Hospital, Sydney, Australia
}

\section{Keywords}

Ageing, Candidate gene; Cerebrovascular disease; Genetics; Leukoaraiosis; Single nucleotide polymorphisms; Small-vessel disease; White matter hyperintensities.

\section{Correspondence}

Professor Perminder S. Sachdev, UNSW School of Psychiatry, NPI, Euroa Centre, Prince of Wales Hospital, Barker Street, Randwick NSW 2031, Australia.

Tel.: +(612)-9382 3763;

Fax: +(612)-9382 3774;

E-mail: p.sachdev@unsw.edu.au

doi: 10.1111/j.1755-5949.2010.00181.x
White matter lesions (WMLs), commonly seen as hyperintensities on T2-weighted MRI scans of healthy elderly individuals, are considered to be related to small vessel disease in the brain, and are often associated with subtle cognitive and functional impairments. WMLs also show a strong correlation with a wide range of neurodegenerative and neuropsychiatric disorders. Although a number of vascular risk factors for WMLs have been identified, genetic factors are also important with twin and family studies reporting high heritability. Mutations in several genes have been described that lead to monogenic disorders manifesting WMLs, such as Fabry disease and CADASIL. Because most individuals with WMLs do not have Mendelian disorders, most of the focus has been on single nucleotide polymorphisms as genetic risk markers for WMLs, either directly or through their interactions with other genes or medical risk factors. Candidate genes examined to date include those involved in cholesterol regulation and atherosclerosis, hypertension, neuronal repair, homocysteine levels, and oxidative stress pathways. In addition, although there have been a few genome-wide linkage studies, only one genomewide association study has been performed. The majority of the genetic findings need independent replication, and studies need to be extended to other candidate genes. Collaborative efforts to examine genome-wide associations in large samples of both sexes of a broad age range using longitudinal studies are necessary. The identification of individuals genetically at risk of developing white matter lesions will have important implications for recognizing the etiology of WMLs and thereby developing clinical intervention strategies for their prevention.

\section{Introduction}

Signal changes in the brain's white matter are commonly seen on magnetic resonance imaging (MRI) scans in healthy elderly individuals as well as in a number of neurological disorders. These changes in the white matter reflect a range of neuropathological findings, including demyelination, axonal loss, proliferation of glial cells, and finally cavitation and infarction [1-3]. The degeneration of macromolecular structure and the high water content in white matter pathological regions is seen as a low-density signal on computed tomography (CT) scans, referred to as "leukoaraiosis." MRI is much more sensitive to white matter pathology, and on T2-weighted and fluid attenuated inversion recovery (FLAIR) sequences, these abnormalities appear as high-intensity signals, the socalled white matter hyperintensities (WMHs) [2]. On diffusion tensor imaging (DTI), white matter abnormality is seen as a change in apparent diffusion coefficients (ADC) and fractional anisotropy (FA), which may be evident in white matter that appears normal on T2-weighted MRI [3]. Because their appearance on neuroimaging varies depending upon the imaging modality used, we will refer to them with the more generic term, white matter lesions (WMLs).

WMLs are a frequent incidental finding in otherwise healthy middle aged and elderly individuals [4], being reported in nearly $50 \%$ of individuals in their mid to 
late 40s [2] and almost invariably by the time individuals reach their late $60 \mathrm{~s}$ and early $70 \mathrm{~s}[5,6]$. When present in "healthy" individuals, WMLs are not without functional significance. In addition to being associated with several impairments including cognitive deficits [7-9], decline in intelligence [10], physical disability [11], and gait abnormality [12], WMLs are correlated with a number of neuropsychiatric disorders such as depression [13], Parkinson's disease [14], Alzheimer's disease [15,16], and late-onset schizophrenia [17]. Moreover, WMLs are a significant component of the ischemic lesion burden in stroke patients [18].

WMLs do not have a specific etiology or pathology, but the lesions commonly seen in asymptomatic elderly individuals seem to be largely ischemic in origin [19]. The white matter of the cerebral hemispheres are largely supplied by long, narrow penetrating arteries and arterioles. Alterations in the structure of these vessels are an invariable feature of WMLs $[1,20]$. Other than age, vascular risk factors such as hypertension, diabetes mellitus, and high homocysteine levels are causal for arteriolosclerosis and have been associated with WMLs in a number of studies $[19,20]$.

Many investigators have subdivided WMLs into two categories: periventricular (PVWMLs) and deep (DWMLs), depending on the proximity of these WMLs to the lateral ventricle wall. This categorization is based on some differences in the pathophysiology and functional significance of PVWMLs from DWMLs [21] even though a considerable overlap exists. Neuropathological differences between DWMLs and PVWMLs have been reported [22], which suggest that although cerebral ischemia is a common etiological factor, other mechanisms may be differentially involved.

Known risk factors account for only a proportion of the variance in the progression of WMLs and recent studies have shown that genetic factors are contributory. The evidence of this initially came from studies of heritability, but there have been a number of recent studies examining WMLs and variation in candidate genes as well as genome-wide associations. The influence of genes on WMLs is either direct or through interactions with other genes or environmental factors.

Studying the genetics of WMLs is important, as these abnormalities can be used as endophenotypes for cerebral small vessel diseases, ischemic stroke, and dementia [23-25]. Endophenotypes are heritable traits associated with an illness in the population that manifest years before the clinical and pathological diagnostic criteria for the disease are met. They, therefore, may be very helpful measures in early diagnosis and treatment of diseases, such as stroke and dementia. This article reviews the cur- rent evidence of genetic influences on WMLs seen in older individuals.

\section{Heritability of WMLs}

Heritability is the proportion of variance of a particular measurable trait, taken at a particular time or age, and high heritability implies genetic determination [26]. Broad-sense heritability, $\mathrm{H}^{2}$, reflects the degree to which a trait is genetically determined, expressed as the ratio of the total genetic variance to the phenotypic variance $\left(\mathrm{V}_{\mathrm{G}} / \mathrm{V}_{\mathrm{P}}\right)$. Narrow sense heritability, also known as heritability, $\mathrm{h}^{2}$, quantifies the degree to which a trait is passed from parent to offspring, expressed as the ratio of the additive genetic variance to the total phenotypic variance $\left(\mathrm{V}_{\mathrm{A}} / \mathrm{V}_{\mathrm{P}}\right)$. Heritability of a trait in humans is estimated by comparing similarities between closely related individuals, in particular twins. Monozygotic twins (MZ) are twice as genetically similar as dizgyotic twins (DZ); therefore, heritability is approximately twice the difference in correlation between MZ and DZ twins.

High heritability of WMLs was reported in a group of older male twins, comprising $74 \mathrm{MZ}$ and $71 \mathrm{DZ}$ pairs $\left(\mathrm{h}^{2}=0.73\right)$ [27]. The heritable nature of WMLs was further supported by a follow-up study based on the same population of male twins which showed a high correlation of adjusted WMLs with the family history score $(\mathrm{r}=$ $0.21)$ [28]. The high heritability of WML volumes was reported in a large family-based sample of the Framingham Heart Study offspring $\left(\mathrm{h}^{2}=0.55\right)$, with similar heritability for men and women. A recent study has replicated the high heritability of WMLs $\left(\mathrm{h}^{2}=0.72\right)$ in 459 Mexican American participants of the San Antonio Family Heart Study [29]. These findings were seen by middle age when symptomatic cerebrovascular disease is uncommon, confirming the earlier observations that the formation of WMLs is under considerable genetic influence. Moreover, the heritability of WMLs remained high among individuals with generally low cerebrovascular brain injury, suggesting that WMLs are likely to be an early marker of adverse brain aging [30].

\section{Monogenic Disorders and WMLs}

Several monogenic disorders manifest as cerebrovascular disease with the development of WMLs. However, most of these disorders are rare and our knowledge is mostly based on case reports rather than large studies.

\section{CADASIL}

Cerebral autosomal dominant arteriopathy with subcortical infarcts and leukoencephalopathy (CADASIL) is the 
most common single gene disorder leading to ischemic stroke [31]. The principal symptoms of CADASIL are migraine attacks, recurrent subcortical ischemic events, and neuropsychiatric symptoms including progressive subcortical dementia [31,32]. Mutations in the NOTCH3 gene, located on chromosome $19 \mathrm{pl} 3.1$ are responsible for CADASIL [33]. Mutations may occur in any one of the NOTCH3 exons 2-23 [23], although mutations in exons 3-6 are responsible for approximately $90 \%$ of cases in Caucasian population [34]. All known mutations associated with CADASIL result in either a gain or loss of cysteine residue in the extracellular domain of the Notch3 protein, which lead to cerebral vascular smooth muscle dysfunction [35]. CADASIL pathology involves small vessel disease, predominantly in the brain [36].

CADASIL is associated with predominant localization of infarcts in the white matter. In one study, all individuals who carried a NOTCH3 mutation showed an increase in WMLs compared to controls $(P=0.004)$. The lesions showed a characteristic pattern in the anterior temporal lobes, the frontal lobes, and the periventricular caps [37]. Another study on 40 CADASIL patients also showed that all patients demonstrated hyperintense lesions on T2-weighted MRI [38]. Heritability of WMLs in 151 CADASIL patients was reported to be 0.63 but after adjustment for age, sex, and diastolic blood pressure, the estimated heritability increased to 0.738 [39]. These results suggest that genetic factors distinct from the causative NOTCH 3 mutations play a key role in disease progression.

\section{Homocystinuria}

Homocystinuria is an autosomal recessive inborn error of methionine metabolism with the majority of cases caused by defects in the gene-encoding cystathionine- $\beta$-synthase. Polymorphisms in the 5,10methylenetetrahydrofolate reductase gene (MTHFR), which lead to deficient remethylation of homocysteine, is another cause of homocystinuria [40]. Reversible demyelination is one of the neurological manifestations of homocystinuria and is similar to other inborn errors of the transsulfuration pathway [41]. WMLs on T2weighted images have been shown in many homocystinuria cases [40,42]. Diffuse white matter changes without evidence of thrombosis [41] and bilateral lesions of the basal ganglia [43] have been also reported.

\section{Genetic Disorders of Arterial and Venous Thrombosis}

Thromboembolic events during the perinatal period are responsible for irreversible brain damage owing to cere- bral hypoxia and neuronal necrosis [44]. The most common genetic risk factors for inherited thrombophilias include mutations in the genes encoding Factor V (F5), prothrombin (F2), Protein S (PROS1), Protein C (PROC), and antithrombin III (AT3) [45]. However, changes in blood levels of antithrombin III [46,47] and prothrombin [48] seem not to be associated with WMLs.

Protein $\mathrm{S}$ is a vitamin K-dependent plasma protein that inhibits blood clotting by serving as a nonenzymatic cofactor for activated protein $\mathrm{C}$ in the inactivation of procoagulant factors V and VIII [49]. Protein S deficiency manifests as an autosomal dominant trait and can be associated with cerebral infarction and WMLs [50]. Protein $\mathrm{C}$ deficiency is an autosomal dominant trait with incomplete penetrance, which primarily causes venous thromboembolism and may be a possible contributor to arterial thrombosis. Congenital protein $\mathrm{C}$ deficiency may be related to acute ischemic infarction [51]. In a large pedigree study of protein C deficiency in hypertensive patients, analyzing brain MRI changes revealed more silent lacunar infarcts in the brains of heterozygous individuals than in controls with no advanced WMLs in either group [52]. Protein $\mathrm{Z}$ is another member of the coagulation cascade and its main role appears to be the degradation of factor $\mathrm{Xa}$ [53]. Protein $\mathrm{Z}$ deficiency is reported to increase the risk of ischemic stroke [54]. Factor V Leiden (FVL) is a variant of Factor $\mathrm{V}$ due to a relatively common genetic polymorphism (R506Q, rs 6025), which may cause cerebral atrophy and porencephalic cystic lesions in infants [55]. In a recent study, ischemic stroke patients who were FVL positive showed more silent infarctions and WMLs than ischemic stroke patients without FVL [56].

\section{MELAS}

Mitochondrial encephalopathy with lactic acidosis and stroke-like episodes (MELAS) is a maternally inherited disorder characterized by recurrent cerebral infarctions [57]. The common MELAS mutation is an alanine to glycine transition (A3243G) in mitochondrial DNA [58]. Moderate losses of myelin and fibrous gliosis were observed as high-signal areas on T2-weighted MRI in the subcortical and deep white matter in a patient suffering from MELAS [59]. In another MELAS case report, brain imaging also indicated generalized atrophy, more marked on the left side, in addition to white matter alterations consistent with a mitochondrial disorder [57]. T2-weighted imaging at both the onset and after 44 days of the stroke-like episode showed left parietal, temporal, and occipital lobe WMLs in another MELAS case [60]. These white matter changes suggest that the stroke-like episodes are related to vasogenic edema, hyperperfusion, and neuronal damage. 


\section{HERNS}

Hereditary endotheliopathy with retinopathy, nephropathy, and stroke (HERNS) is an autosomal dominant inherited, multisystemic disease presenting with leukoencephalopathy, progressive visual loss, and nephropathy. Linkage analysis has mapped the disease locus to chromosome 3p21 [61], although the disease gene has not been identified. Brain MRI scans of HERNS patients have identified contrast-enhancing cerebral lesions with surrounding vasogenic edema [62].

\section{Fabry disease}

Fabry disease (FD, Anderson-Fabry disease) is a rare $\mathrm{X}$-linked inborn disorder, caused by deficient activity of the lysosomal enzyme alpha-galactosidase A. More than 400 mutations have been reported in $\alpha$-galactosidase A gene (GLA), ranging from small deletions to complex rearrangements, which results in partial or complete inactivity of the enzyme. Progressive accumulation of undegraded glycosphingolipids leads to reduced cerebral flow velocity and impaired cerebral autoregulation [63], causing ischemic complications involving the kidneys, heart, and brain [64]. Central nervous system involvement is indicated by the cerebrovascular events observed in FD patients [65]. The most common abnormality is the presence of cerebral white matter lesions [66-68] including numerous silent lesions, increasing with age, mainly in small perforant arteries (periventricular white matter, brainstem, cerebellum, and basal ganglia) [63]. The deep periventricular and posterior predominant WMLs in FD are best observed in FLAIR sequences [69], but DTI may be an even more sensitive technique [68]. For female FD carriers, cerebrovascular events are as frequent as frequent as in affected males [70] and they also show MRI abnormalities similar to those of affected males [71].

It has been shown that a number of genetic variants including polymorphisms in the interleukin-6, endothelial nitric oxide synthase, factor $\mathrm{V}$, and PROZ genes were all independently associated with cerebral lesions in FD patients. This was the first time that the modifying effects of these genes were shown on FD, a single gene disorder [72]. Therefore, the presence of genetic modifiers is likely in other inborn errors of metabolism and needs to be investigated further.

\section{Complex Genetic Disorders}

As noted earlier, disorders with Mendelian inheritance are an infrequent cause of WMLs. Most of the genetic ba- sis of WMLs must therefore be sought in the small effects of multiple genes and their interactions with other genes and/or environmental factors. Such genes have been investigated for single nucleotide polymorphisms (SNPs), traditionally investigating one or more SNPs within a single candidate gene, or more recently through genomewide association studies.

\section{Genome-Wide Studies}

Genome-wide studies use high-throughput genotyping technologies to examine hundreds of thousands of markers to identify genetic variants and high-risk haplotypes associated with complex disease. There are two common methodological approaches in genome-wide studies: association and linkage. In genome-wide association studies (GWAS), a correlation between a specific genetic variation and trait variation is investigated in a sample of unrelated individuals, while in linkage studies, trait loci that cosegregate with a specific genomic region is studied within families [73]. To our knowledge, only one GWAS has been undertaken examining WMLs to date.

The only genome-wide study that found significant evidence of linkage for WMLs volume was performed in multiple generations of a large population-based cohort-the Framingham Heart Study. An initial scan for WML volume used 387 highly polymorphic linkage markers in 2259 family members. The significant linkage peak was located on chromosome 4p16.2 (LOD score $=$ 3.69) [74]. The linkage between WMLs and chromosome 4 was observed again in a subsequent genome-wide association and linkage study of 100,000 SNPs for 705 members of the largest Framingham families [25]. This linkage region includes the gene for Huntington disease (HTT), genes associated with WMLs risk factors, including the GRK4 gene that has been associated with hypertension [75], and also genes responsible for mitochondrial functioning. Genome-wide association analyses between SNPs and WMLs on the same sample revealed other SNPs that may influence WMLs. Although some of these SNPs were not within known genes, several SNPs were from biologically interesting genes such as the glial growth factor (NRGl), the potassium channel protein (KCNMAl), and a tight junction component (CLDN10) [25]. The results of this explorative GWAS require replication.

Three other genome-wide linkage studies reported suggestive evidence of linkage for WMLs on chromosome 5 [76], chromosome 1 [29,76), and chromosome 11 [77]. The study performed by Turner et al. [77], showed the most overlap with the Framingham study findings. The significant linkage region seen in the Framingham study corresponded to one of the linkage regions for brain 
atrophy (0-24 cM from 4pter) in this study [77]. Turner et al. also reported a linkage region on chromosome 12 for ventricular volume (12pl2-12q12), which was shown to harbor some SNPs linked with regional and cerebral volumes in the second Framingham genome-wide study [25]. Moreover, within the chromosome 1 1q23.1-1 1q25 region for WMLs, the Framingham investigators noted that one SNP in the $\beta$-site amyloid $\beta$ precursor proteincleaving enzyme 1 gene (BACEl; rs126179) was associated with parietal brain volume. Variations in BACEl have been associated with Alzheimer disease [78].

These findings suggest that there are chromosomal regions and SNPs within these regions that are linked to MRI measures of structural brain phenotypes, such as WMLs and brain volumes. This suggests that there may be common molecular pathways leading to brain lesions and brain atrophy.

It is important to note that none of the significant linkage peaks determined in genome-wide studies have been reliably replicated. Moreover, the associations reported in the candidate gene studies, which will be discussed later, were not seen in genome-wide studies. This lack of overlap may be due to a number of reasons. First, although the high heritability estimates for WMLs suggests genetics plays a major role in its development it does not give any details regarding the type/s of genetic variation involved. The current results suggest that WMLs are influenced by many genes with only small to moderate effects [29]. Second, differences in the methodologies between studies such as study designs, different sized samples, racial differences (e.g., Mexican Americans vs. European), disease status and varied MRI methodologies for WMLs evaluation, suggests that the different results observed by these studies may be study specific. Finally, most of the studies had limited power and may not detect linkage regions or SNPs of small effect size. Therefore, replication of linkage or association findings in independent samples will be necessary before undertaking any further functional investigations.

Although the GWAS is a comprehensive and unbiased approach of identifying genetic variants of complex human diseases, there are several issues that arise with this study design. These include high potential rates of false positive results due to multiple testing, the necessity for large sample sizes, lack of information on the functions of identified genes in many cases, and insensitivity to rare and structural variants [79].

\section{Candidate Gene Approach}

A number of candidate genes that are involved in putative pathways leading to the formation and progression of WMLs have been examined, as summarized in Table 1. A smaller number of studies have also assessed gene-gene interactions, which are detailed in Table 2.

\section{Cholesterol Regulation and Atherosclerosis-Related Genes}

The most important gene in this group, Apolipoprotein E (APOE), encodes a plasma glycoprotein (ApoE) involved in the transport of cholesterol and other hydrophobic molecules across the membrane of various cells [80]. In addition to being involved in lipoprotein transport, ApoE plays an important role in neuronal repair, including dendrite formation and synaptogenesis, which is an important process in restoring the integrity of the brain in response to injury $[81,82]$. An important APOE polymorphism is denoted by one of three alleles (E2-E4). The APOE E4 allele is due to a T-C transition at codon 112 , occurs in approximately $25 \%$ of the Caucasian population, and has been implicated in neuronal dysfunction [82]. The E4 allele is a well-established risk factor for late-onset Alzheimer's disease [83] in a dosage-dependent manner [84]. The presence of APOE E4 has a large impact on longevity, cardiovascular diseases, and other neurological disorders including stroke, cerebral amyloid angiopathy, Lewy body disease, multiple sclerosis, Parkinson's disease, and several others. This raises the question whether ApoE may participate in a range of molecular neurodegenerative mechanisms that might be common for several disorders [85].

Studies have shown that E4 allele is not only associated with vascular risk factors for WMLs [27,81] but also with WML-associated disorders, particularly cognitive impairment and dementia [86,87]. The E4 allele increases the effect of cardiovascular disease on brain volumes and white matter changes. However, the presence of the E4 allele alone is not a risk factor for brain atrophy or WMLs [88]. The APOE E4 allele also increases depressive symptoms in people with WMLs [89]. In a large population of the Rotterdam Scan Study, APOE E4 carriers had significantly increased deep WML volumes than did subjects with the E3/E3 genotype, but this was not found for periventricular WMLs. This could be due to a different vascularization pattern between deep and periventricular white matter. Participants with both hypertension and at least one E4 allele had the highest volumes of both types of WMLs [81]. On the other hand, other studies failed to show any significant association for APOE E4 with WMLs either in a population sample [90] or in patients with Alzheimer's disease [91]. Some studies have shown that the E2 allele could be a risk factor for the development of WMLs $[92,93]$. The mechanisms underlying this association are unclear, it has been suggested this could be 
Table 1 Genetic polymorphisms associated with White Matter Lesions (WMLS)

\begin{tabular}{|c|c|c|c|c|c|c|}
\hline Gene & Polymorphism & P/OR & $n$ & Sample & Association & Reference \\
\hline \multicolumn{7}{|c|}{ Apolipoprotein E (APOE) } \\
\hline & APOE E4 & $P<0.03$ & 396 & Population $^{a}$ & $C V D^{b}$ & [88] \\
\hline & APOE E4 & $P<0.005$ & 92 & Population & Depression $^{b}$ & [89] \\
\hline & APOE E4 & $P=0.016$ & 971 & Population & Hypertension ${ }^{b}$ & {$[81]$} \\
\hline & APOE E2/E3 & $\mathrm{OR}=3.0 ; P=0.01$ & 280 & Population & Positive $^{c}$ & [92] \\
\hline & APOE E4 & NS & $93 / 583$ & $\mathrm{Cl} /$ Control & None & {$[116]^{d}$} \\
\hline & APOE E4 & NS & $55 / 66$ & AD/Control & None & {$[91]$} \\
\hline & APOE genotype & NS & $215 / 20$ & Dementia $/$ Control & None & [90] \\
\hline \multicolumn{7}{|c|}{ Angiotensinogen (AGT) } \\
\hline & AGT Promoter-20:C & $P=0.017$ & 410 & Population & Positive & [104] \\
\hline & AGT M235T & $P<0.001$ & 267 & Population & Positive & [104] \\
\hline & AGT M235T & $P=0.008$ & $>1000$ & Population & Positive & [103] \\
\hline \multicolumn{7}{|c|}{ Angiotensin II receptor type 1(AGTR1) } \\
\hline & AGTR1 A1166C & $P<0.005$ & 134 & Population & Positive & {$[110]^{d}$} \\
\hline & AGTR1 A1166C & $P<0.05$ & 93 & Hypertensive & Negative $^{c}$ & [107] \\
\hline & AGTR1 A1166C & NS & $129 / 27$ & Ischemic stroke/Population & None & {$[111]^{d}$} \\
\hline & AGTR1 A1166C & NS & 510 & Acute $\mathrm{BI}$ & None & [112] \\
\hline \multicolumn{7}{|c|}{ Angiotensin I-converting enzyme (ACE) } \\
\hline & ACE D/D genotype & $P<0.05$ & 182 & Dementia & Positive & [114] \\
\hline & ACE D allele & $\mathrm{OR}=2.95 ; P<0.01$ & $129 / 27$ & Ischemic stroke/ Population & Positive & {$[111]^{d}$} \\
\hline & ACE D/D genotype & $P<0.0005$ & 229 & LA combined with infarcts & Positive & [115] \\
\hline & ACE D/D genotype & $\mathrm{OR}=4.44 ; P=0.022$ & 60 & Hypertensive & Positive & [106] \\
\hline & ACE D allele & NS & 134 & Population & None & {$[110]^{d}$} \\
\hline & ACE D allele & NS & 93 & Hypertensive & None & [107] \\
\hline \multicolumn{7}{|c|}{ Aldosterone synthase (CYP11B2) } \\
\hline & CYP11B2 TT genotype & $\mathrm{OR}=4.61 ; P=0.009$ & 829 & Population & Positive & [122] \\
\hline \multicolumn{7}{|c|}{ Methylenetetrahydrofolate reductase (MTHFR) } \\
\hline & MTHFR A1298C & $P=0.001$ & 68 & PCSNL receiving MTX & Positive & [128] \\
\hline & MTHFR C677T & $P=0.017$ & $178 / 85$ & Depressed/Non-depressed & Positive & [129] \\
\hline \multicolumn{7}{|c|}{ Brain-derived neurotrophic factor (BDNF) } \\
\hline & BDNF V66M & $P=0.044$ & $199 / 113$ & Depressed/Non-depressed & Positive & [132] \\
\hline \multicolumn{7}{|c|}{ Paraoxonase (PON1) } \\
\hline & PON1 L55M LL genotype & $\mathrm{OR}=2.65 ; P=0.004$ & 264 & Population & Positive & [134] \\
\hline & PON1 Q191R & $\mathrm{OR}=6 ; P=0.02$ & $104 / 113$ & ONFH/Control & Positive & [140] \\
\hline \multicolumn{7}{|c|}{ Nitric Oxide Synthase (NOS3) } \\
\hline & NOS3 G894T & $P<0.05$ & 93 & Hypertensive & Positive & [107] \\
\hline & NOS3 G894T & NS & $300 / 600$ & SVD/Control & None & [144] \\
\hline
\end{tabular}

NS, not significant; CVD, cardiovascular diseases; Cl, cerebral infarction; AD, Alzheimer's disease; BI, brain infarction; LA: leukoaraiosis; PCSNL, primary CNS lymphoma; MTX, methotrexate; ONFH, osteonecrosis of the femoral head; SVD, small vessel disease.

apopulation: community sample.

${ }^{\mathrm{b}}$ Association observed only in interaction with stated medical conditions.

${ }^{\mathrm{c}}$ Positive association: the genotype mentioned or the mutant allele/amino acid is associated with more WMLs, Negative association: genotype mentioned or the mutant allele/amino acid is associated with less WMLs.

${ }^{\mathrm{d}}$ Non-Caucasian population.

${ }^{\text {e}}$ Dementia: Alzheimer's disease (AD), non-AD dementia or mixed neuropsychiatric disorder.

through impairment in repair mechanisms, which may result in more damage after cerebral ischemia [92].

\section{Hypertension-Related Genes}

The observed association between WMLs and hypertension raises the possibility that genes involved in the regulation of blood pressure may be implicated. Some of the genes code for enzymes in the renin-angiotensin system (RAS). RAS is a complex enzymatic pathway, and is involved in the regulation of blood pressure and fluid balance [94]. When the arterial blood pressure is low, renin, a proteolytic enzyme, is secreted from the kidneys to act on the inactive angiotensinogen (AGT) to form 
Table 2 Gene-gene interactions as risk factors for white matter lesions (WMLs)

\begin{tabular}{|c|c|c|c|c|c|}
\hline Gene 1 & Gene 2 & P/OR & $\mathrm{N}$ & Sample & Reference \\
\hline $\begin{array}{l}\text { Methylenetetrahydrofolate } \\
\text { reductase (MTHFR) 677TT }\end{array}$ & APOE E4/E4 + E4/E3 & $P<0.005 ; \mathrm{OR}=2.47$ & $315 / 646$ & Leukoaraiosis/Control & {$[117]^{a}$} \\
\hline MTHFR 677TT & APOE E2/E2 + E2/E3 & $P<0.0005 ; \mathrm{OR}=2.52$ & $315 / 646$ & Leukoaraiosis/Control & {$[117]^{a}$} \\
\hline MTHFR 677TT & $\begin{array}{l}\text { Angiotensin I-converting } \\
\text { enzyme(ACE)D/D }\end{array}$ & $P<0.0005 ; \mathrm{OR}=4.90$ & $229 / 362$ & Leukoaraiosis/Control & {$[115]^{a}$} \\
\hline Apolipoprotein E (APOE) E2 allele & ACE D/D & $P<0.05 ; \mathrm{OR}=2.11$ & $315 / 646$ & Leukoaraiosis/Control & {$[117]^{a}$} \\
\hline Angiotensinogen (AGT) M235T & ACE D allele & $P<0.01 ; O R=11.70$ & $93 / 583$ & Cerebral Infarction/Control & {$[116]^{b, c}$} \\
\hline Angiotensinogen (AGT) M235T & APOE E4 allele & NS & $93 / 583$ & Cerebral Infarction/Control & {$[116]^{b}$} \\
\hline $\begin{array}{l}\text { AGT M235T } \\
\text { ACE I/D } \\
\text { AGTR1 A1166C } \\
\text { NOS3 G894T }\end{array}$ & $\begin{array}{l}\text { No interaction between } \\
\text { these polymorphisms }\end{array}$ & NS & 93 & Hypertensive subjects & [107] \\
\hline $\begin{array}{l}\text { AGT M235T } \\
\text { AGTR1 A1166C } \\
\text { ACE I/D }\end{array}$ & $\begin{array}{l}\text { No interaction between } \\
\text { these polymorphisms }\end{array}$ & NS & 60 & Hypertensive subjects & {$[106]$} \\
\hline
\end{tabular}

a Unclear if control samples were in Hardy-Weinberg equilibrium.

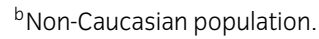

${ }^{\mathrm{C}}$ Genotype frequencies for the ACE control group were not in Hardy-Weinberg equilibrium.

angiotensin I, which is in turn hydrolyzed by angiotensinconverting enzyme (ACE) to form the active Angiotensin II. Angiotensin II causes blood vessels to constrict, resulting in increased blood pressure. Angiotensin II also stimulates the secretion of the hormone aldosterone, which causes an increase in the fluid volume of the body ultimately increasing blood pressure. ACE, which is present in the endothelial cells of the blood vessels, has an additional effect in degrading bradykinin, an active vasodilator [95]. Genetic polymorphisms in relation to the major enzymes in this pathway have been examined in relation to small vessel disease and WMLs.

\section{Angiotensinogen}

The angiotensinogen gene (AGT), located on chromosome 1q42, has a large number of polymorphisms [94]. A missense mutation is found in exon 2, encoding threonine instead of methionine at position 235 (M235T; rs699). This mutation and a nucleotide substitution in the promoter region (G-6A) are in tight linkage disequilibrium and have therefore been investigated in a number of studies $[96,97]$. AGT polymorphisms have been associated with blood pressure, arterial stiffness, and other cardiovascular phenotypes. The M235T polymorphism has been linked to hypertension and cardiovascular disease [98] as well as coronary artery disease and myocardial infarction [99-102]. The presence of the threonine variant has been associated with WMLs and lacunes, inde- pendent of arterial hypertension [103]. Two follow-up studies showed that this polymorphism is linked to lesion progression as well $[104,105]$. On the other hand, two other studies, both with small sample sizes, found no association between WMLs and the M235T polymorphism [106, 107].

Production of AGT is regulated mainly at the transcriptional level. Two common polymorphisms in the promoter region at positions G-6A and A-20C have been shown to alter transcriptional efficiency. One study on the association of microangiopathy-related cerebral damage (MARCD) with sequence alterations in the AGT promoter region investigated four polymorphic sites, which create five haplotypes. Individuals homozygous for the -20:c allele showed a significant association with MARCD [108], whereas the association of the -6 : a polymorphism showed borderline significance. Moreover, one haplotype $(-6: \mathrm{a},-20: \mathrm{c},-153: \mathrm{g},-218: \mathrm{g})$ predicted MARCD considerably better than the -20 :c allele, independent of hypertension. If other studies can replicate these results, this haplotype may serve as a genetic marker for the identification of individuals prone to develop WMLs.

\section{Angiotensin II Receptor type 1 (AGTR1)}

Angiotensin II interacts with two subtypes of cell surface receptors. Type 1 receptors mediate the major cardiovascular effects of angiotensin II [109]. The AGTRl gene 
maps to 3q21-q25 and more than 20 SNPs have been identified; although none are located in the coding region. The Al166C polymorphism (rs5186) is one of the most widely studied SNPs in the ATGRl gene. The C allele has been shown to increase ATGRl expression and is consequently a risk factor for cardiovascular diseases $[94,110]$. However, there is inconsistency in the literature whether the $\mathrm{C}$ allele is a risk [110] or a protective allele [107] for WMLs, whereas other studies have failed to show any association of this polymorphism with WMLs [111,112]. This could be partly explained by ethnic differences in the samples used as the presence of $\mathrm{C}$ allele as a risk factor has been only seen in non-Caucasians.

\section{Angiotensin I-Converting Enzyme (ACE)}

More than 100 polymorphisms have been identified in the ACE gene, located on chromosome 17q23. The best documented polymorphism is an insertion/deletion (I/D) of a 287-base-pair DNA fragment within intron 16, which accounts approximately for $40 \%$ of the total variance of plasma ACE [94].

The D allele of the ACE gene appears to be associated with a higher risk of atherosclerotic complications including coronary heart disease, myocardial infarction, and stroke although it is not associated with hypertension directly [113]. However, the deletion allele (D) in hypertensive patients has been shown to be a risk factor for the prevalence of WMLs [106]. The first study to report the association of ACE DD genotype with WMLs was performed in dementia patients [114]. In another study, the ACE D allele was significantly more frequent in patients with leukoaraiosis combined with infarcts than in the control group. However, in the same study, those who had leukoaraiosis with no infarction failed to show this association [115]. The ACE D allele was later shown to be associated with lacunar infarction and CT-determined WMLs [1 111$]$, while other studies have failed to show any associations with the ACE I/D polymorphism and WMLs [107,110].

Some studies have shown that the interaction of certain unfavorable genetic mutations with the ACE D allele can contribute to the evolution of leukoaraiosis. An early Japanese study observed a synergistic effect of the $\mathrm{T}$ allele of the AGT gene and the D allele of the ACE gene on the incidence of cerebral infarctions [116]. However, due to the small sample size and wide confidence interval of the odds ratio, and more importantly the fact that ACE I/D genotype frequencies for the controls were not in Hardy-Weinberg equilibrium, the reported association should be considered spurious and the results require replication. The homozygous ACE D/D genotype in combination with the APOE E4 or E2 allele has also been reported to contribute significantly to the development of leukoaraioasis [117] (Table 2).

\section{Aldosterone Synthase}

Aldosterone has essential roles in maintaining intravascular volume and blood pressure. Aldosterone synthase is the enzyme responsible for the biosynthesis of aldosterone. Mutations in this gene (CYP11B2) cause either hypertension or hypotension [118]. CYP11B2 is located on chromosome 8q24.3 and is composed of nine exons [119]. A polymorphism in the transcriptional regulatory region of this gene was described in 1995 [120], in which a $\mathrm{C}$ for $\mathrm{T}$ substitution at position -344 occurs in a putative binding site for the steroidogenic transcription factor SF-1. This substitution causes an increased binding of SF1 to the $-344 \mathrm{C}$ allele, resulting in an altered transcription rate, and a decrease in aldosterone synthase and aldosterone levels $[120,121]$. This locus is an important candidate region in essential hypertension [121]. The T allele was shown to be associated with an increased risk of severe WMLs independent of classic vascular risk factors, such as hypertension [122]. This result was confirmed by the observation that the $\mathrm{C}$ allele is protective for severe leukoaraiosis in patients with lacunar infarctions [112], although, this association was marginally significant.

\section{Homocysteine-Related Genes}

In individuals without homocystinuria, methylenetetrahydrofolate reductase gene (MTHFR) mutations have been associated with high levels of serum total homocysteine (tHcy), and impaired DNA synthesis. MTHFR is a folic acid related enzyme, which plays a crucial role in remethylation of homocysteine to methionine, and thereby the biosynthesis of DNA and RNA [123]. The MTHFR gene is located on chromosome 1 p36.6 and up to 24 variants have been reported [124]. Two of the most studied polymorphisms are located in the coding region; a cysteine to threonine substitution at position 677 (C677T, rs 1801133 ) and an alanine to cysteine at position 1298 (A1298C, rs1801131), both of which result in high blood tHcy levels.

Leukoaraiosis has been reported to be positively correlated with the tHcy level and conversely correlated with the serum folate level [125]. The MTHFR C677T polymorphism has been shown to be associated with symptomatic subcortical infarction [126], silent brain infarcts [127], and white matter changes [128]. One study reported the association of MTHFR C677T variant with WMLs [129]. The MTHFR A1298C polymorphism is also reported to be linked with white matter changes [128]. 
One study examined the MTHFR C677T and ACE I/D polymorphisms in leukoaraiosis. Neither the homozygous nor the heterozygous MTHFR C677T mutation alone was found to be a risk factor for leukoaraiosis. The homozygous MTHFR 677TT mutation combined with the ACE D/D genotype was significantly more frequent in the leukoaraiosis cohort than in the controls [115]. The influence of APOE genotypes in pair-wise combinations with the MTHFR 677TT or ACE D/D mutation in patients with leukoaraiosis were examined later. The homozygous MTHFR 677TT mutation in combination with the APOE $\mathrm{E} 4 / \mathrm{E} 4$ and E3/E4 genotypes or in combination with the APOE E2/E2 plus E2/E3 genotypes can contribute to the development of leukoaraioasis. The positive interactions between these genotypes can be a result of their reciprocally facilitating effects [117] (Table 2). However, these two studies have not mentioned whether the allele and genotype frequencies were in Hardy-Weinberg equilibrium, therefore the results need to be replicated.

\section{Regeneration-Related Genes}

In the presence of neuronal injury, suboptimal regenerative processes may contribute to the development of WMLs. Although a number of nerve growth factors are involved in neuronal growth and regeneration, only the brain-derived neurotrophic factor (BDNF) has been examined in relation to WMLs. In the affected white matter of the ischemic brain, BDNF produced by glial cells plays an important role in protecting and promoting the regeneration of nerve fibers [130]. The BDNF gene (BDNF) is located between the boundary of $11 \mathrm{pl} 3$ and $11 \mathrm{pl} 4$ [131] and the most common polymorphism, a substitution of valine by methionine (V66M, rs6265), is associated with reduced production of BDNF. Carriers of the BDNF 66M allele have shown both greater WML volumes in older individuals [132] and an age-related decline in the splenium fractional anisotropy [133].

\section{Oxidative Stress-Related Genes}

It is hypothesized that during the process of ageing, oxidative stress increases, leading to high levels of lipid peroxidation, and thereby greater severity of WMLs in the elderly [134]. There are many genes involved in oxidative stress pathways. Polymorphisms in some genes such as the paraoxonase gene (PON) family and nitric oxide synthase gene (NOS3) promote oxidative stress, whilst mutations in other genes such as the mice P66Shc gene whose product generates mitochondrial reactive oxygen species (ROS) [135], protect cells against oxidative damage. In addition to polymorphisms in genomic DNA, mitochondrial DNA mutations may also be important as mitochondria are the major source of reactive oxygen species (ROS) in the cell [136]. Thus, mitochondrial DNA mutations may influence oxidative stress levels. Moreover, gene expression changes in the genes responsible for stress and inflammatory responses and energy metabolism pathways are key contributory factors in oxidative stress-related aging processes [136].

\section{Paraoxonase Gene (PON) Family}

The PON family includes three genes, PON1, PON2 and PON3, aligned next to each other on chromosome 7. Members of the paraoxonase gene family encode high-density lipoprotein (HDL)-related glycoproteins with multienzymatic properties [137]. The paraoxonases act as important protectors against cellular damage from toxic agents, such as organophosphates and oxidized lipids found in plasma low-density lipoproteins. Moreover, they may protect against development of atherosclerosis [138].

Although relationships between polymorphisms in the PON gene cluster and cardiovascular diseases have been demonstrated previously [139], only PONl (7q21.3) has been investigated for association with white matter changes. In the Austrian Stroke Prevention Study, homozygotes for the leucine substitution at coding position 55 (L55M, rs854560), were reported to have a greater extent of WMLs at baseline [134] and this was a predictive factor for their progression over 3 years [105,134]. This study failed to show a significant association between a polymorphism in the coding region, which substitutes glutamine for arginine (Q191R) and the progression of WMLs. However, in patients with osteonecrosis of the femoral head (ONFH), the Q191R and not the L55M polymorphism showed an association with WMLs [140]. It is noteworthy that WMLs were present at an unexpectedly high frequency $(>50 \%)$ in young patients with ONFH [141].

\section{Nitric Oxide Synthase}

Oxygen free radicals seem to play an important role in central nervous system injury after cerebral ischemia. Nitric oxide synthase is the enzyme catalyzing the formation of nitric oxide, a neuronal messenger molecule and oxygen radical identified in several models of cerebral ischemia. The nitric oxide synthase gene (NOS3), is mapped to 7q35-q36 [142] and three common polymorphisms have been identified: a promoter nucleotide substitution (T-786C), a deletion/insertion polymorphism within intron 4 (intron 4ab) and a coding variant (G894T) which is reported to increase the proteolytic activity of the enzyme [143]. The first study investigating the 
association of NOS3 polymorphisms with small-vessel disease found positive results only in association with lacunar infarcts and not with ischemic leukoaraiosis [144]. However, a later study, reported the association of G894T polymorphism with WMLs in hypertensive individuals [107].

\section{Discussion}

Examining the genetics of WMLs is important for a number of reasons: these lesions are common in older individuals, they are relatively easy to quantify using MRI, they are a marker of small vessel disease in the brain, they have high heritability, and WMLs may be a useful endophenotype for small vessel diseases as well as dementia.

The association of WMLs with some monogenic disorders is further evidence of the role of genetic factors in the causation of these lesions. However, monogenic disorders account for a very small proportion of cases with WMLs, and the high prevalence of these lesions in the population argues for a complex genetic etiology, comprising multiple small gene effects. Because of the lack of success of traditional linkage and candidate gene association studies to observe consistent results, researchers are also beginning to use genome-wide association studies to discover new genetic variants associated with WMLs.

The genetic investigation of WMLs is still in its infancy, with few candidate genes examined and only one genome-wide association study undertaken. There have been also a few linkage studies performed, providing suggestive evidence of genetic linkage for WMLs, but the actual gene(s) involved are yet to be discovered. Among all candidate genes investigated, the most consistent findings were for AGT, where the initial findings were replicated in a large population study $(\mathrm{N}>1000)$. The complexity of this field of investigation must, however, be acknowledged. Firstly, there is wide variation in the quantitation of WMLs due to the different techniques being used. While CT is relatively insensitive to this pathology, T2-weighted imaging may not be the optimum method. Even when FLAIR imaging is used to exclude dilated perivascular spaces that are difficult to distinguish from WMLs on routine $\mathrm{T} 2$-weighted imaging, there are considerable differences in the detection of WMLs depending upon the scanner make, field strength and imaging protocol being used. It is also noteworthy that DTI will often detect abnormal diffusivity in white matter regions that appear normal on T2-weighted imaging. A final decision on what constitutes WMLs can therefore be difficult, and it is likely that different investigators will use different criteria to examine the same phenotype, which is likely to make consistency of results difficult to achieve.
There are other considerations in this research. It is not clear whether genetic factors have a direct effect on small vessel disease or act through a number of known risk factors such as hypertension and diabetes. It is therefore important to take these factors into consideration and to examine the interactions between genetic and other risk factors. Factors may be different for men and women. Although some of the known risk factors for small vessel disease are more common in men, WMLs are slightly, but significantly more prevalent in women [145] suggesting that there may be different mechanisms operating in men and women. It is also possible that the risk factors will vary according to age.

A major limitation of the current data is that the genetic studies have been cross-sectional. Longitudinal data suggest that WMLs are progressive, and the determinants of progression may not be the same as cross-sectional studies suggest [146]. However, currently, the main predictor of rate of progression is the extent of WMLs at baseline, which suggests that the same factors are likely to be involved.

Given these caveats, larger collaborative studies are needed, which measure multiple potential risk factors and include individuals of both sexes over a wide age range. These studies should ideally be longitudinal to enable the examination of genetic factors that influence the progression of WMLs. Standardized measures for the identification and quantitation of WMLs are needed so that replication is possible. It is also important to examine the functional correlates of WMLs to determine the impact of these pathologies on domains such as cognition and health. Gene-environment and gene-physical health relationships should also be examined. This promises to be a fruitful area of neurogenetic investigation in the future.

\section{Acknowledgments}

This work was supported by National Health \& Medical Research Council of Australia Program Grants (NHMRC IDs: 350833 and 510217). The authors also thank the Dementia Collaborative Research Centre (DCRC) for the PhD scholarship to A.A.

\section{Conflict of Interest}

The authors declare no conflict of interest.

\section{References}

1. Vanswieten JC, Vandenhout JHW, Vanketel BA, Hijdra A, Wokke JHJ, Vangijn J. Periventricular lesions in the white matter on magnetic-resonance-imaging in the 
elderly - a morphometric correlation with arteriolosclerosis and dilated perivascular spaces. Brain 1991; 114:761-774.

2. Wen W, Sachdev PS, Li JJ, Chen X, Anstey KJ. White matter hyperintensities in the forties: Their prevalence and topography in an epidemiological sample aged 44-48. Hum Brain Mapp 2009;30:1155-1 167.

3. Taylor WD, Hsu E, Krishnan KR, MacFall JR. Diffusion tensor imaging: Background, potential, and utility in psychiatric research. Biol Psychiatry 2004;55:201-207.

4. Longstreth WT, Manolio TA, Arnold A, et al. Clinical correlates of white matter findings on cranial magnetic resonance imaging of 3301 elderly people - The cardiovascular health study. Stroke 1996;27:1274-1282.

5. Fazekas F. Magnetic resonance signal abnormalities in asymptomatic individuals: Their incidence and functional correlates. Eur Neurol 1989;29:164-168.

6. Wen W, Sachdev P. The topography of white matter hyperintensities on brain MRI in healthy 60- to 64-year-old individuals. Neuroimage 2004;22: 144-154.

7. Gunning-Dixon FM, Raz N. The cognitive correlates of white matter abnormalities in normal aging: A quantitative review. Neuropsychology 2000;14:224-232.

8. Au R, Massaro JM, Wolf PA, et al. Association of white matter hyperintensity volume with decreased cognitive functioning: The Framingham Heart Study. Arch Neurol 2006;63:246-250.

9. Bunce D, Anstey KJ, Christensen H, Dear K, Wen W, Sachdev P. White matter hyperintensities and within-person variability in community-dwelling adults aged 60-64 years. Neuropsychologia 2007;45:2009-2015.

10. Garde E, Lykke Mortensen E, Rostrup E, Paulson OB. Decline in intelligence is associated with progression in white matter hyperintensity volume. J Neurol Neurosurg Psychiatry 2005;76:1289-1291.

11. Sachdev PS, Wen W, Christensen H, Jorm AF. White matter hyperintensities are related to physical disability and poor motor function. J Neurol Neurosurg Psychiatry 2005;76:362-367.

12. Sakakibara R, Hattori T, Uchiyama T, Yamanishi T. Urinary function in elderly people with and without leukoaraiosis: Relation to cognitive and gait function. J Neurol Neurosurg Psychiatry 1999;67:658-660.

13. Herrmann LL, Le Masurier M, Ebmeier KP. White matter hyperintensities in late life depression: A systematic review. J Neurol Neurosurg Psychiatry 2008;79:619-624.

14. Beyer MK, Aarsland D, Greve OJ, Larsen JP. Visual rating of white matter hyperintensities in Parkinson's disease. Mov Disord 2006;21:223-229.

15. Rezek DL, Morris JC, Fulling KH, Gado MH. Periventricular white matter lucencies in senile dementia of the Alzheimer type and in normal aging. Neurology 1987;37:1365-1368.
16. Capizzano AA, Acion L, Bekinschtein T, et al. White matter hyperintensities are significantly associated with cortical atrophy in Alzheimer's disease. J Neurol Neurosurg Psychiatry 2004;75:822-827.

17. Sachdev P, Brodaty H. Quantitative study of signal hyperintensities on T2-weighted magnetic resonance imaging in late-onset schizophrenia. Am J Psychiatry 1999;156:1958-1967.

18. Wen W, Sachdev PS. Extent and distribution of white matter hyperintensities in stroke patients: The Sydney Stroke Study. Stroke 2004;35:2813-2819.

19. Pantoni L, Garcia JH. Pathogenesis of leukoaraiosis: A review. Stroke 1997;28:652-659.

20. de Leeuw FE, de Groot JC, Oudkerk M, Witteman JCM, Hofman A, van Gijn J, Breteler MMB. Hypertension and cerebral white matter lesions in a prospective cohort study. Brain 2002; 125:765-772.

21. Sachdev P, Wen W. Should we distinguish between periventricular and deep white matter hyperintensities?. Stroke 2005;36:2342-2343; author reply 3-4.

22. Fazekas F, Kleinert R, Offenbacher H, et al. Pathologic correlates of incidental MRI white matter signal hyperintensities. Neurology 1993;43: 1683-1689.

23. Markus H. Genes for stroke. J Neurol Neurosurg Psychiatry 2004;75:1229-1231.

24. Vermeer SE, Hollander M, van Dijk EJ, Hofman A, Koudstaal PJ, Breteler MM. Silent brain infarcts and white matter lesions increase stroke risk in the general population: The Rotterdam Scan Study. Stroke 2003;34:1126-1129.

25. Seshadri S, DeStefano AL, Au R, et al. Genetic correlates of brain aging on MRI and cognitive test measures: A genome-wide association and linkage analysis in the Framingham Study. BMC Med Genet 2007;8(Suppl 1): S15.

26. Visscher PM, Hill WG, Wray NR. Heritability in the genomics era-concepts and misconceptions. Nat Rev Genet 2008;9:255-266.

27. Carmelli D, DeCarli C, Swan GE, Jack LM, Reed T, Wolf PA, Miller BL. Evidence for genetic variance in white matter hyperintensity volume in normal elderly male twins. Stroke 1998;29:1177-1181.

28. Reed T, Kirkwood SC, DeCarli C, et al. Relationship of family history scores for stroke and hypertension to quantitative measures of white-matter hyperintensities and stroke volume in elderly males. Neuroepidemiology 2000; 19:76-86.

29. Kochunov P, Glahn D, Winkler A, et al. Analysis of genetic variability and whole genome linkage of whole-brain, subcortical, and ependymal hyperintense white matter volume. Stroke 2009;40: 3685-3690.

30. Atwood LD, Wolf PA, Heard-Costa NL, Massaro JM, Beiser A, D'Agostino RB, DeCarli C. Genetic variation in 
white matter hyperintensity volume in the Framingham Study. Stroke 2004;35:1609-1613.

31. Dong Y, Hassan A, Zhang Z, Huber D, Dalageorgou C, Markus HS. Yield of screening for CADASIL mutations in lacunar stroke and leukoaraiosis. Stroke 2003;34:203-205.

32. Viitanen M, Kalimo H. CADASIL: Hereditary arteriopathy leading to multiple brain infarcts and dementia. Ann N Y Acad Sci 2000;903:273-284.

33. Joutel A, Corpechot C, Ducros A, et al. Notch3 mutations in CADASIL, a hereditary adult-onset condition causing stroke and dementia. Nature 1996;383:707-710.

34. Markus HS, Martin RJ, Simpson MA, Dong YB, Ali N, Crosby AH, Powell JF. Diagnostic strategies in CADASIL. Neurology 2002;59:1 134-1138.

35. Read SJ, Parsons AA, Harrison DC, et al. Stroke genomics: approaches to identify, validate, and understand ischemic stroke gene expression. J Cereb Blood Flow Metab 2001;21:755-778.

36. Rafalowska J, Dziewulska D, Fidzianska A. CADASIL: What component of the vessel wall is really a target for Notch 3 gene mutations?. Neurol Res 2004;26:558-562.

37. Lesnik Oberstein SA, Van Den Boom R, Middelkoop HA, et al. Incipient CADASIL. Arch Neurol 2003;60:707-712.

38. Van Den Boom R, Lesnik Oberstein SA, Ferrari MD, Haan J, van Buchem MA. Cerebral autosomal dominant arteriopathy with subcortical infarcts and leukoencephalopathy: MR imaging findings at different ages-3rd-6th decades. Radiology 2003;229:683-690.

39. Opherk C, Peters N, Holtmannspotter M, Gschwendtner A, Muller-Myhsok B, Dichgans M. Heritability of MRI lesion volume in CADASIL: Evidence for genetic modifiers. Stroke 2006;37:2684-2689.

40. Takenaka T, Shimomura T, Nakayasu H, Urakami K, Takahashi K. Effect of folic acid for treatment of homocystinuria due to 5,10-methylenetetrahydrofolate reductase deficiency. Rinsho Shinkeigaku 1993;33:1140-1145.

41. Vatanavicharn N, Pressman BD, Wilcox WR. Reversible leukoencephalopathy with acute neurological deterioration and permanent residua in classical homocystinuria: A case report. J Inherit Metab Dis 2008. Available from: http://www.springerlink.com/content/ t8026052q02w27j1/[Accessed 22 January 2008].

42. Hamano H, Nanba A, Nagayama M, Takizawa S, Shinohara Y. An adult case of homocystinuria probably due to methylenetetrahydrofolate-reductase deficiency-treatment with folic acid and the course of coagulation-fibrinolysis parameters. Rinsho Shinkeigaku 1996;36:330-335.

43. Berardelli A, Thompson PD, Zaccagnini M, Giardini O, D’Eufemia P, Massoud R, Manfredi M. Two sisters with generalized dystonia associated with homocystinuria. Mov Disord 1991;6:163-165.
44. Tzoufi M, Giotopoulou S, Papadimitriou P, Dokou E, Kolaitis NI, Siamopoulou A, Manfredi M. Genetic risk factors associated with thrombosis in children with congenital neurologic disorders. J Child Neurol 2005;20:509-512.

45. Ahmad A. Genetics of cerebral venous thrombosis. J Pak Med Assoc 2006;56:488-490.

46. Intiso D, Di Rienzo F, Rinaldi G, et al. Brain MRI white matter lesions in migraine patients: Is there a relationship with antiphospholipid antibodies and coagulation parameters?. Eur J Neurol 2006;13: 1364-1369.

47. Nishiwaki Y, Takebayashi T, Omae K, Ishizuka C, Nomiyama T, Sakurai H. Relationship between the blood coagulation-fibrinolysis system and the subclinical indicators of arteriosclerosis in a healthy male population. J Epidemiol 2000;10:34-41.

48. Fu JH, Mao J, Xue XD, You K. Early diagnostic significance and dynamic pattern of DWI compared with conventional MRI in newborns with neonatal cerebral infarction. Zhonghua Er Ke Za Zhi 2007;45: 360-364.

49. Dahlback B, Stenflo J. High molecular weight complex in human plasma between vitamin K-dependent protein $\mathrm{S}$ and complement component $\mathrm{C} 4 \mathrm{~b}$-binding protein. Proc Natl Acad Sci USA. 1981;78:2512-2516.

50. Wu LH, Chen WH, Lien LM, Huang CH, Chiu HC. AIDS with acute cerebral infarct: a case report. Acta Neurol Taiwan 2005; 14:74-78.

51. Yang FC, Hsu CH, Lin JC, Chen CY, Lee JT. Inherited protein $\mathrm{C}$ deficiency with acute ischemic stroke in a young adult: A case report. Blood Coagul Fibrinolysis 2008; 19:601-604.

52. Kario K, Sakata T, Higashikawa M, Katayama Y, Hoshide S, Shimada K, Miyata T. Silent cerebral infarcts in basal ganglia are advanced in congenital protein C-deficient heterozygotes with hypertension. Am J Hypertens 2001;14(8 Pt 1):818-822.

53. Han X, Fiehler R, Broze GJ, Jr. Isolation of a protein Z-dependent plasma protease inhibitor. Proc Natl Acad Sci USA 1998;95:9250-9255.

54. Vasse M, Guegan-Massardier E, Borg JY, Woimant F, Soria C. Frequency of protein $\mathrm{Z}$ deficiency in patients with ischaemic stroke. Lancet 2001;357:933-934.

55. Voudris KA, Skardoutsou A, Vagiakou EA. Congenital microcephaly in two infants with the factor V Leiden mutation. J Child Neurol 2002;17:905-907.

56. Haapaniemi E, Helenius J, Jakovljevic D, et al. Ischaemic stroke patients with heterozygous factor $\mathrm{V}$ Leiden present with multiple brain infarctions and widespread atherothrombotic disease. Thromb Haemost 2009;101: 145-150.

57. Longo N, Schrijver I, Vogel H, et al. Progressive cerebral vascular degeneration with mitochondrial encephalopathy. Am J Med Genet A 2008;146:361-367. 
58. Majamaa K, Turkka J, Karppa M, Winqvist S, Hassinen IE. The common MELAS mutation A3243G in mitochondrial DNA among young patients with an occipital brain infarct. Neurology 1997;49:1331-1334.

59. Fujii T, Okuno T, Ito M, et al. CT, MRI, and autopsy findings in brain of a patient with MELAS. Pediatr Neurol 1990;6:253-256.

60. Ito H, Mori K, Harada M, et al. Serial brain imaging analysis of stroke-like episodes in MELAS. Brain Dev 2008;30:483-488.

61. Jen J, Cohen AH, Yue Q, Stout JT, Vinters HV, Nelson S, Baloh RW. Hereditary endotheliopathy with retinopathy, nephropathy, and stroke (HERNS). Neurology 1997;49:1322-1330.

62. Seifried C, Sitzer M, Jen J, Auburger G. HERNS. A rare, hereditary, multisystemic disease with cerebral microangiopathy. Nervenarzt 2005;76:1191-1192, 4-5.

63. Clavelou P, Besson G, Elziere C, et al. Neurological aspects of Fabry's disease. Rev Neurol (Paris) 2006; 162:569-580.

64. Germain DP, Benistan K, Halimi P. Chiari type I malformation in four unrelated patients affected with Fabry disease. Eur J Med Genet 2006;49:419-425.

65. Moore DF, Herscovitch P, Schiffmann R. Selective arterial distribution of cerebral hyperperfusion in Fabry disease. J Neuroimaging 2001;11:303-307.

66. Fellgiebel A, Mazanek M, Whybra C, et al. Pattern of microstructural brain tissue alterations in Fabry disease: A diffusion-tensor imaging study. $J$ Neurol 2006;253:780-787.

67. Ginsberg L, Manara R, Valentine AR, Kendall B, Burlina AP. Magnetic resonance imaging changes in Fabry disease. Acta Paediatr Suppl 2006;95:57-62.

68. Albrecht J, Dellani PR, Muller MJ, et al. Voxel based analyses of diffusion tensor imaging in Fabry disease. $J$ Neurol Neurosurg Psychiatry 2007;78:964-969.

69. Crutchfield KE, Patronas NJ, Dambrosia JM, Frei KP, Banerjee TK, Barton NW, Schiffmann R. Quantitative analysis of cerebral vasculopathy in patients with Fabry disease. Neurology 1998;50:1746-1749.

70. Saip S, Uluduz D, Erkol G. Fabry disease mimicking multiple sclerosis. Clin Neurol Neurosurg 2007; 109:361-363.

71. Mitsias P, Levine SR. Cerebrovascular complications of Fabry's disease. Ann Neurol 1996;40:8-17.

72. Altarescu G, Moore DF, Schiffmann R. Effect of genetic modifiers on cerebral lesions in Fabry disease. Neurology 2005;64:2148-2150.

73. Borecki IB, Province MA. Linkage and association: Basic concepts. Adv Genet 2008;60:51-74.

74. DeStefano AL, Atwood LD, Massaro JM, et al. Genome-wide scan for white matter hyperintensity: The Framingham Heart Study. Stroke 2006;37:77-81.

75. Wang HK, Fung HC, Hsu WC, et al. Apolipoprotein E, angiotensin-converting enzyme and kallikrein gene polymorphisms and the risk of Alzheimer's disease and vascular dementia. J Neural Transm 2006;113: 1499-1509.

76. Turner ST, Fornage M, Jack CR, Jr., Mosley TH, Kardia SL, Boerwinkle E, de Andrade M. Genomic susceptibility loci for brain atrophy in hypertensive sibships from the GENOA study. Hypertension 2005;45:793-798.

77. Turner ST, Fornage M, Jack CR, et al. Genomic susceptibility Loci for brain atrophy, ventricular volume, and leukoaraiosis in hypertensive sibships. Arch Neurol 2009;66:847-857.

78. Rogaeva E, Meng Y, Lee JH, et al. The neuronal sortilin-related receptor SORL1 is genetically associated with Alzheimer disease. Nat Genet 2007;39:168-177.

79. Manolio TA, Collins FS, Cox NJ, et al. Finding the missing heritability of complex diseases. Nature 2009;461:747-753.

80. Hagberg JM, Wilund KR, Ferrell RE. APO E gene and gene-environment effects on plasma lipoprotein-lipid levels. Physiol Genomics 2000;4:101-108.

81. de Leeuw FE, Richard F, de Groot JC, van Duijn CM, Hofman A, Van Gijn J, Breteler MM. Interaction between hypertension, apoE, and cerebral white matter lesions. Stroke 2004;35:1057-1060.

82. Petrella JR, Mattay VS, Doraiswamy PM. Imaging genetics of brain longevity and mental wellness: The next frontier?. Radiology 2008;246:20-32.

83. Corder EH, Saunders AM, Strittmatter WJ, et al. Gene dose of apolipoprotein E type 4 allele and the risk of Alzheimer's disease in late onset families. Science 1993;261:921-923.

84. Farrer LA, Cupples LA, Haines JL, et al. Effects of age, sex, and ethnicity on the association between apolipoprotein E genotype and Alzheimer disease. A meta-analysis. APOE and Alzheimer Disease Meta Analysis Consortium. JAMA 1997;278:1349-1356.

85. Cedazo-Minguez A. Apolipoprotein E and Alzheimer's disease: Molecular mechanisms and therapeutic opportunities. J Cell Mol Med 2007;11:1227-1238.

86. Lahoz C, Schaefer EJ, Cupples LA, et al. Apolipoprotein E genotype and cardiovascular disease in the Framingham Heart Study. Atherosclerosis 2001;154: 529-537.

87. van Straaten EC, Harvey D, Scheltens P, et al. Periventricular white matter hyperintensities increase the likelihood of progression from amnestic mild cognitive impairment to dementia. J Neurol 2008;255:1302-1308.

88. DeCarli C, Reed T, Miller BL, Wolf PA, Swan GE, Carmelli D. Impact of apolipoprotein E epsilon4 and vascular disease on brain morphology in men from the NHLBI twin study. Stroke 1999;30:1548-1553.

89. Nebes RD, Vora IJ, Meltzer CC, et al. Relationship of deep white matter hyperintensities and apolipoprotein $\mathrm{E}$ genotype to depressive symptoms in older adults 
without clinical depression. Am J Psychiatry 2001;158:878-884.

90. Bigler ED, Lowry CM, Kerr B, et al. Role of white matter lesions, cerebral atrophy, and APOE on cognition in older persons with and without dementia: The Cache County, Utah, Study of Memory and Aging. Neuropsychology 2003;17:339-352.

91. Sawada H, Udaka F, Izumi Y, Nishinaka K, Kawakami H, Nakamura S, Kameyama M. Cerebral white matter lesions are not associated with apoE genotype but with age and female sex in Alzheimer's disease. Journal of Neurology Neurosurgery and Psychiatry 2000;68: 653-656.

92. Schmidt R, Schmidt H, Fazekas F, et al. Apolipoprotein E polymorphism and silent microangiopathy-related cerebral damage. Results of the Austrian Stroke Prevention Study. Stroke 1997;28:951-956.

93. Lemmens R, Gorner A, Schrooten M, Thijs V. Association of apolipoprotein E epsilon2 with white matter disease but not with microbleeds. Stroke 2007;38:1185-1188.

94. Jeunemaitre X. Genetics of the human renin angiotensin system. J Mol Med 2008;86:637-641.

95. Savaskan E. The role of the brain renin-angiotensin system in neurodegenerative disorders. Curr Alzheimer Res 2005;2:29-35.

96. Jeunemaitre X, Gimenez-Roqueplo AP, Celerier J, Corvol P. Angiotensinogen variants and human hypertension. Curr Hypertens Rep 1999;1:31-41.

97. Tsai CT, Fallin D, Chiang FT, et al. Angiotensinogen gene haplotype and hypertension: Interaction with ACE gene I allele. Hypertension 2003;41:9-15.

98. Staessen JA, Kuznetsova T, Wang JG, Emelianov D, Vlietinck R, Fagard R. M235T angiotensinogen gene polymorphism and cardiovascular renal risk. J Hypertens 1999;17:9-17.

99. Katsuya T, Koike G, Yee TW, et al. Association of angiotensinogen gene T235 variant with increased risk of coronary heart disease. Lancet 1995;345:1600-1603.

100. Kamitani A, Rakugi H, Higaki J, et al. Enhanced predictability of myocardial infarction in Japanese by combined genotype analysis. Hypertension 1995;25:950-953.

101. Ludwig EH, Borecki IB, Ellison RC, et al. Associations between candidate loci angiotensin-converting enzyme and angiotensinogen with coronary heart disease and myocardial infarction: The NHLBI Family Heart Study. Ann Epidemiol 1997;7:3-12.

102. Winkelmann BR, Russ AP, Nauck M, et al. Angiotensinogen M235T polymorphism is associated with plasma angiotensinogen and cardiovascular disease. Am Heart J 1999;137(4 Pt 1):698-705.

103. van Rijn MJ, Bos MJ, Isaacs A, et al. Polymorphisms of the renin-angiotensin system are associated with blood pressure, atherosclerosis and cerebral white matter pathology. J Neurol Neurosurg Psychiatry 2007;78: 1083-1087.

104. Schmidt R, Schmidt H, Fazekas F, et al. Angiotensinogen polymorphism M235T, carotid atherosclerosis, and small-vessel disease-related cerebral abnormalities. Hypertension 2001;38:110-115.

105. Schmidt R, Schmidt H, Kapeller P, Lechner A, Fazekas F. Evolution of white matter lesions. Cerebrovasc Dis 2002;13(Suppl 2):16-20.

106. Sierra C, Coca A, Gomez-Angelats E, Poch E, Sobrino J, de la Sierra A. Renin-angiotensin system genetic polymorphisms and cerebral white matter lesions in essential hypertension. Hypertension 2002;39(2 Pt 2):343-347.

107. Henskens LH, Kroon AA, van Boxtel MP, Hofman PA, de Leeuw PW. Associations of the angiotensin II type 1 receptor A1 166C and the endothelial NO synthase G894T gene polymorphisms with silent subcortical white matter lesions in essential hypertension. Stroke 2005;36:1869-1873.

108. Schmidt H, Fazekas F, Kostner GM, van Duijn CM, Schmidt R. Angiotensinogen gene promoter haplotype and microangiopathy-related cerebral damage: Results of the Austrian Stroke Prevention Study. Stroke 2001;32:405-412.

109. Murphy TJ, Alexander RW, Griendling KK, Runge MS, Bernstein KE. Isolation of a cDNA encoding the vascular type-1 angiotensin II receptor. Nature 1991;351:233-236.

110. Takami S, Imai Y, Katsuya T, et al. Gene polymorphism of the renin-angiotensin system associates with risk for lacunar infarction. The Ohasama study. Am J Hypertens 2000;13:121-127.

111. Mizuno T, Makino M, Fujiwara Y, et al. Reninangiotensin system gene polymorphism in Japanese stroke patients. In: Abe K, editor. Molecular mechanisms and epochal therapeutics of ischemic stroke and dementia, Amsterdam: Elsevier Science Bv, 2003; pp. 83-90.

112. Brenner D, Labreuche J, Pico F, Scheltens P, Poirier O, Cambien F, Amarenco P. The renin-angiotensinaldosterone system in cerebral small vessel disease. J Neurol 2008;255:993-1000.

113. Staessen JA, Wang JG, Ginocchio G, et al. The deletion/insertion polymorphism of the angiotensin converting enzyme gene and cardiovascular-renal risk. J Hypertens 1997;15(12 Pt 2):1579-1592.

114. Amar K, MacGowan S, Wilcock G, Lewis T, Scott M. Are genetic factors important in the aetiology of leukoaraiosis? Results from a memory clinic population. Int J Geriatr Psychiatry 1998;13:585-590.

115. Szolnoki Z, Somogyvari F, Kondacs A, Szabo M, Fodor L. Evaluation of the roles of common genetic mutations in leukoaraiosis. Acta Neurol Scand 2001;104:281-287. 
116. Nakata Y, Katsuya T, Rakugi H, et al. Polymorphism of angiotensin converting enzyme, angiotensinogen, and apolipoprotein E genes in a Japanese population with cerebrovascular disease. Am J Hypertens 1997;

10(12 Pt 1):1391-1395.

117. Szolnoki Z, Somogyvari F, Kondacs A, Szabo M, Fodor L, Bene J, Melegh B. Specific APO E genotypes in combination with the ACE D/D or MTHFR 677TT mutation yield an independent genetic risk of leukoaraiosis. Acta Neurol Scand 2004;109: 222-227.

118. Isaji M, Mune $\mathrm{T}$, Takada $\mathrm{N}$, et al. Correlation between left ventricular mass and urinary sodium excretion in specific genotypes of CYP11B2. J Hypertens 2005;23:1149-1157.

119. Taymans SE, Pack S, Pak E, Torpy DJ, Zhuang Z, Stratakis CA. Human CYP11B2 (aldosterone synthase) maps to chromosome 8q24.3. J Clin Endocrinol Metab 1998;83:1033-1036.

120. White PC, Slutsker L. Haplotype analysis of CYP11B2. Endocr Res 1995;21:437-442.

121. Kumar NN, Benjafield AV, Lin RC, Wang WY, Stowasser $\mathrm{M}$, Morris BJ. Haplotype analysis of aldosterone synthase gene (CYP11B2) polymorphisms shows association with essential hypertension. J Hypertens 2003;21:1331-1337.

122. Verpillat $\mathrm{P}$, Alperovitch A, Cambien F, Besancon V, Desal H, Tzourio C. Aldosterone synthase (CYP11B2) gene polymorphism and cerebral white matter hyperintensities. Neurology 2001;56:673-675.

123. Ueland PM, Hustad S, Schneede J, Refsum H, Vollset SE. Biological and clinical implications of the MTHFR C677T polymorphism. Trends Pharmacol Sci 2001;22:195-201.

124. Sibani S, Christensen B, O'Ferrall E, Saadi I, Hiou-Tim F, Rosenblatt DS, Rozen R. Characterization of six novel mutations in the methylenetetrahydrofolate reductase (MTHFR) gene in patients with homocystinuria. Hum Mutat 2000; 15:280-287.

125. Sachdev P, Parslow R, Salonikas C, et al. Homocysteine and the brain in midadult life: evidence for an increased risk of leukoaraiosis in men. Arch Neurol 2004;61: 1369-1376.

126. Notsu Y, Nabika T, Park HY, Masuda J, Kobayashi S. Evaluation of genetic risk factors for silent brain infarction. Stroke 1999;30:1881-1886.

127. Kohara K, Fujisawa M, Ando F, Tabara Y, Niino N, Miki $\mathrm{T}$, Shimokata H. MTHFR gene polymorphism as a risk factor for silent brain infarcts and white matter lesions in the Japanese general population: The NILS-LSA Study. Stroke 2003;34:1130-1135.

128. Linnebank M, Moskau S, Jurgens A, et al. Association of genetic variants of methionine metabolism with methotrexate-induced CNS white matter changes in patients with primary CNS lymphoma. Neuro Oncol 2009; 11:2-8.
129. Hong ED, Taylor WD, McQuoid DR, Potter GG, Payne ME, Ashley-Koch A, Steffens DC. Influence of the MTHFR C677T polymorphism on magnetic resonance imaging hyperintensity volume and cognition in geriatric depression. Am J Geriatr Psychiatry 2009; 17:847-855.

130. Sato Y, Chin Y, Kato T, et al. White matter activated glial cells produce BDNF in a stroke model of monkeys. Neurosci Res 2009;65:71-78.

131. Hanson IM, Seawright A, van Heyningen V. The human BDNF gene maps between FSHB and HVBS1 at the boundary of 11p13-p14. Genomics 1992;13:1331-1333.

132. Taylor WD, Zuchner S, McQuoid DR, et al. The brain-derived neurotrophic factor VAL66MET polymorphism and cerebral white matter hyperintensities in late-life depression. Am J Geriatr Psychiatry 2008; 16:263-271.

133. Kennedy KM, Rodrigue KM, Land SJ, Raz N. BDNF val66met polymorphism influences age differences in microstructure of the corpus callosum. Front Human Neurosci 2009;3:7.

134. Schmidt R, Schmidt H, Fazekas F, et al. MRI cerebral white matter lesions and paraoxonase PON1 polymorphisms: Three-year follow-up of the austrian stroke prevention study. Arterioscler Thromb Vasc Biol 2000;20:1811-1816.

135. Purdom S, Chen QM. p66(Shc): At the crossroad of oxidative stress and the genetics of aging. Trends $\mathrm{Mol}$ Med. 2003;9:206-210.

136. Wei YH, Wu SB, Ma YS, Lee HC. Respiratory function decline and DNA mutation in mitochondria, oxidative stress and altered gene expression during aging. Chang Gung Med J 2009;32:113-132.

137. Lu H, Zhu J, Zang Y, Ze Y, Qin J. Cloning, purification, and refolding of human paraoxonase-3 expressed in Escherichia coli and its characterization. Protein Expr Purif 2006;46:92-99.

138. Draganov DI, Teiber JF, Speelman A, Osawa Y, Sunahara R, La Du BN. Human paraoxonases (PON1, PON2, and PON3) are lactonases with overlapping and distinct substrate specificities. J Lipid Res 2005;46:1239-1247.

139. Schmidt H, Schmidt R, Niederkorn $\mathrm{K}$, et al. Paraoxonase PON1 polymorphism leu-Met54 is associated with carotid atherosclerosis: Results of the Austrian Stroke Prevention Study. Stroke 1998;29: 2043-2048.

140. Hadjigeorgiou GM, Malizos K, Dardiotis E, et al. Paraoxonase 1 gene polymorphisms in patients with osteonecrosis of the femoral head with and without cerebral white matter lesions. J Orthop Res 2007;25:1087-1093.

141. Hadjigeorgiou GM, Karantanas AH, Zibis A, Dardiotis E, Aggelakis K, Papadimitriou A, Malizos K. Increased frequency of white matter lesions in patients with 
osteonecrosis (WMLeOn) of the femoral head. Eur $J$ Radiol 2004;50:278-284.

142. Robinson LJ, Weremowicz S, Morton CC, Michel T. Isolation and chromosomal localization of the human endothelial nitric oxide synthase (NOS3) gene. Genomics 1994;19:350-357.

143. Tesauro M, Thompson WC, Rogliani P, Qi L, Chaudhary $\mathrm{PP}$, Moss J. Intracellular processing of endothelial nitric oxide synthase isoforms associated with differences in severity of cardiopulmonary diseases: Cleavage of proteins with aspartate vs. glutamate at position 298. Proc Natl Acad Sci USA 2000;97:2832-2835.
144. Hassan A, Gormley K, O'Sullivan M, et al. Endothelial nitric oxide gene haplotypes and risk of cerebral small-vessel disease. Stroke 2004;35: 654-659.

145. de Leeuw FE, de Groot JC, Achten E, et al. Prevalence of cerebral white matter lesions in elderly people: A population based magnetic resonance imaging study. The Rotterdam Scan Study. J Neurol Neurosurg Psychiatry 2001;70:9-14.

146. Sachdev P, Wen W, Chen X, Brodaty H. Progression of white matter hyperintensities in elderly individuals over 3 years. Neurology 2007;68:214-222. 